\title{
Proverbs and Narratives: An Inherited Knowledge System of Child Rearing and Caring in Rural Cultural Setting
}

\author{
Md. Abdur Rahman ${ }^{1}$ and Asif Ekbal Arif ${ }^{2 *}$ \\ ${ }^{1}$ Department of Anthropology, Comilla University, Bangladesh \\ ${ }^{2}$ Department of Anthropology, Jatiya Kabi Kazi Nazrul Islam University, Bangladesh \\ *Corresponding author: Asif Ekbal Arif, Assistant Professor, Department of Anthropology, Jatiya Kabi Kazi Nazrul Islam University, \\ Bangladesh
}

\section{Introduction}

This paper aims to write a research proposal on 'Archaeology of inherited wisdom: interpreting proverbs and narratives related to infants and young childcare in rural Bangladesh'. This study has investigated knowledge system of rearing and caring of infants and young children as focal point of view where their parents and relatives share the knowledge on infants and childcare from the oral literature such as proverbs and narratives to procreate infants and child. The modern biomedical and modern knowledge system spread various propagandas by stating folk wisdom as useless and irrelevant in the perspective of modern age of scientific rationality. The global cultural flows of infants and young childcare occupy almost every parts of the world through electronic media, western academicians and the medical industry as a whole. This study has basically started to its journey with the aim of interpreting proverbs and narratives as insightful thoughts of folk wisdom which are holistically applied for the procreation of infants and young children. However, this study has proposed a thoughtful design to draw research tools, systematic way of collecting primary data, the purpose and process of reviewing relevant literature, the statement of this research as an issue of investigation, the rationale of this study, the theoretical and conceptual backdrops, the systematic way of recording and the interpretation of field data in the form of ethnographic writing [1].

\section{Background of this Study}

This study has been designed through the background scenario of Bangladesh because infants and young childcare issue is a fascinating issue of investigation among the Government and Non-Government organization. They basically explain various structural and institutional processes which facilitate, constrain, and manipulate infants and young child health care. All the study implies modern biomedical and nutritional perspective that fails to interpret the local literature including proverbs and narratives which are full of insights to procreate, educate and manage knowledge on health care. Such types of knowledge are transmitted orally, and these are the experiential knowledge where proverbs and narratives are the popular forms of such oral literature of the local people. In such situation, it is imperative to record such forms of cultural knowledge or folk wisdom and in this context; this study has aimed to interpret proverbs and narratives as fundamental source of knowledge related to infants and young childcare [2].

\section{Use of proverbs and narrative thought}

Professor Wolfgang Mieder's presentation in memory of Alan Dundes in Tartu and the title of his article in this journal The Proof of the Proverb is in the Probing points straight to my subject matter: The use of proverbs and narrative thought. Probing processes in real situations has a lot to do with molding and modifying the truthfulness of a proverb through narrative way of thinking. In more or less big questions we try to find the ways to analyze the situation in order to act or at least to react. If one focuses upon the use of proverbs or proverb-like sayings, namely on the functions of them in social interaction, one will find questions concerning the same themes as in folk narrative research in general: selective memory, reconstruction of experiences, explaining and reasoning about the past, giving instructions and warnings for the future, encouraging or amusing each other, etc. This type of research proved to be possible through a combination of social psychological approach and deep knowledge of folklore data. Rethinking of archival or ethno-methodologically collected data and new records from everyday situations made it possible to reanalyze the data and find various functions of proverbs in social interaction. The research, which was approved for a doctoral thesis in the Department of Social Psychology at the University of Helsinki, owes a great deal to folkloristic and anthropological research done among different cultures (Lauhakangas 2004). Further it has connections with the early days of psychology - namely, Wilhelm Wundt's folk psychology (1912). This branch remained in the margin for a 
long time (because of the triumph of experimental psychology) But if we take W. Wundt's thoughts under consideration now, we notice that their spirit was quite close to narrative research. The theoretical and empirical principle in the research of the functions of proverbs in social interaction was to study the common sense or everyday thinking in its cultural and social contexts. The role of language and cultural conditions was now reconsidered, after $\mathrm{W}$. Wundt's days, as a challenge to understand social interaction. In one of his introductions to proverb collections, MattiKuusi called proverbs signs of situations and emotional loadings (Kuusi 1988). He probably meant their unique linguistic properties as cultural tools of man, but this description could also be understood from the point of view of the social use of proverbs. What was their function in everyday encounters and conversations? It was not enough for a culturally orientated social psychologist to state that proverbs were a nice or tough-lived part of tradition transferred as cultural modes of thought. A general list of the functions of proverbs given even by any leading paremiologist would not be satisfying. This kind of research could be culturally valid only if it covered as many aspects as possible of any speech situations where people use proverbs [3].

\section{Why does a proverb emerge into a speech situation?}

Any social or personal context where people use proverbs in different cultures (and throughout history) could be considered equally interesting from the point of view of the above formulated general question. Accordingly, proverbs with contexts were collected for this research from other scholars around the world and not only from Finnish folklore archives and fiction. Besides, the author observed everyday situations and kept a notebook about people's ways to use proverbs in the media. The following example shows how people even nowadays are keen to use proverbs, although they call them clichés or well-worn expressions. In a Finnish radio broadcast, editor Juha Kulmanen interviews JariLuoto, an Under Secretary of State, about population policy. The interviewer poses one of his questions in a rhetorical way: "The rich will become richer and the poor will grow poorer. This is an old phrase, but it holds good." (cf. 'He who has is given, he who has little is taken from' or 'Money is drawn to money'.) The interviewee addressed shows his agreement. The conversation continues and for a closing statement Luoto says: "It is a stock phrase but holds good: If there were no UN, we would have to invent it." (A radio broadcast in Yle One, 24.10.2005.) For the study of contexts, a new term, 'the proverb speech', was formulated. It can be simply defined as a kind of speech where a proverb or a proverb-like saying is used (inner speech included). By building a many-sided classification of the functions of 'proverb speech' based on the material of context examples, it could also be better explained why proverbs had special linguistic structures. At least the emotional tendencies and social strategies of people to recall proverbs could be better understood. The themes of the social interaction of proverbs, in terms of their imagery, are interesting as such (see MattiKuusi's thematic classification of proverbs in Lauhakangas 2001). But themes in proverbs seem to have a connection to the function of proverb speech as a narrative mode of thought [4].

\section{The narrative strength of proverbs in social contexts}

Proverbs are multifunctional and flexible instruments of everyday reasoning, although they may maintain solidified attitudes or traditional modes of thought of a certain culture. A proverb can be considered as a piece of advice concerning a recommended direction of action (although it is not literally a piece of advice). Proverbs are propositions loaded with hidden feelings, wishes and intentions of the speaker. They can serve as tools to cover individual opinions in public interactive situations. Like in rhetoric in general the proverbs we use in our speech (and in our inner speech, too) protect our personal attitudes by referring to the third party. They give us persuasiveness by appealing to an authority. The ability to use proverbs leans on common rules and recipes and it is a part of facilities for outlining and organizing quickly and effectively things which we experience in everyday situations. Reasoning, classifying, comparing and explaining are mechanisms by which people aim at while creating hierarchy and consistency to the contents of commonplace thinking. Using proverbs means that people can deal with their relations to each other and/or to things. People can explain to themselves what happens or what has happened, and they can give explanations to any behavior they have observed. Ready-made models make it easy to orientate in these types of situations and demands of social life, but the drawback of this is that those models, for example proverbs, guide us to see situations named by them. Thus, we are not able to see or notice the (possible) distinguishing features of them. The mundane philosophy of proverbs or proverb use deals with ethical and pragmatic questions. They are about questions how things are or how they should be; about issues how things can be recognized and what we can know about them. They are brought out in situations where people feel emotional tension and need smooth actions. They mean authorized wisdom called for when people should decide how to explain things. Proverbs are brought to conversations to make calculations of profitability: How do we influence on things or on our life? and How and when it is wise to act or let things go?

KwesiYankah (1989) wrote about a broad or wider consciousness of language and how the user of proverbs has a creative ability to utter them in a convincing way (and also an ability to convice her/himself). The proverb users have ready-made opinions about urgent questions which they seem to strengthen with suitable proverbs. But in any case, the attention of listeners focuses on creditability of the proverb mentioned. The narrative strength concentrates just on the proverb, if we examine the use of it, namely the proverb in its social context. Jokes or anecdotes are not the most critical contents of any conversation or presentation, neither is a proverb or a proverb-like expression. But anyway they may be the best remembered parts in argumentation [5].

\section{Statement of the Problem}

The problem statement of this present study draws from the background information and the gaps between the reviewing existing literatures. People in rural settings in Bangladesh from diverse socio-economic and demographic features and are still 
dependent on such inherited wisdom in relation to infants and child health care knowledge through sharing such experiential knowledge system. Beside this, due to global technological and modern biomedical knowledge flows, people face constrains to keep their inherited knowledge tradition on infants and childcare. However, various literatures on infants and young childcare in Bangladesh evident that people are pursued or bound to keep the touch of modern biomedical scientific knowledge system with the influences of national and global forces by public, private and tertiary initiatives of medicalization of infants and young child. In such situation, this study has aimed to find out the knowhow how people are still thinking about proverbs and narratives related to the knowledge on infants and young childcare in the rural context.

\section{Objectives of this Study}

The objective of this study has been drawn from the statement of the research problem. However, this section covers the following broad and specific objectives.

\section{Broad objective}

The broad objective of this study was to explore the architecture of inherited wisdom including proverbs and narratives related to infants and young childcare in the study area.

\section{Specific objectives}

The specific objectives of this study were;

a) To interpret the structural and functional attributes of proverbs and narratives about infants and child health care and how people think about, symbolize and distinguish proverbs and narratives on the proposed area of investigation.

b) To explore the nature of the knowledge either it covers holistic view about infants and young childcare in the study context.

c) To explain the processes and procedures of transmission of such oral knowledge related to the knowledge on infants and young childcare in the study area.

d) To identify the factors which contextualize, manipulate, and constrain such knowledge system in case of infants and young childcare in the study area.

\section{Rationale of this Study}

This study claims rationality because of a variety of embedded reasons. First of all, knowledge on infants and young childcare through sharing and transmitting proverbs and narratives which contain folk wisdom that needs to explore and record. Second, this knowledge transmitted orally and by generation to generation that covers the experiential knowledge about infants and young child care which are very cheap in availability in terms of biomedical knowledge but full of value and local wisdom and efficacy in terms of the real practitioners of such inherited knowledge system. Finally, on the academic ground, this study gives a floor to explore such knowledge system from the perspective of the generator and the user not because of the easier access of data but such type of studies are rare in anthropological academic field in Bangladesh and this study has hoped that the academic resources will be enriched by this study.

\section{Theoretical and conceptual framework}

The structural and Functional aspects of proverbs and narratives can be interpreted on the theoretical lens of 20th century European linguistic thinkers. Ferdinand Saussurean semiology has a successful root in the study of folk elements of culture and anthropology of linguistic phenomena including language and its social and cultural contexts as well. Anthropology has a tradition to conduct ethnographic research on 'speech and speaking'. Saussurean structural linguistic integrates two elementary parts of language including 'langue' (the language or tongue mainly the grammar of a language) and 'parole' (word or speech). Proverbial aspects of a speech community can be analyzed on the basis of the Saussurian dichotomy naming langue/parole. Proverbs in every language or speech community bear grammatical structure such as morphological, phonological and syntactic structure along with the semantic analytical principle which associates its meaning depending on the linguistic environment of the speech community. The major aim of semantic analytical principle is to excavate the meaning of the speech, words or sings and symbols.

The pragmatic analytical tools can also be applied in case of studying proverbs in rural cultural contexts. The pragmatic analysis of proverb associates threefold element including statement, evaluation and prescription. The statement includes what is coded, said or represented in the form of speech or written, the evaluation associates what is meant by the statement or the understanding the underlying meaning principles, and prescription is about what is suggested to forecast about future learning through the statement.

The semiotic analytical frame of analyzing proverb can also be put into attention to study proverbs. Park and Milica [6] have identified three manifold aspects of function of proverb these are; "ideational (language construes human experience), interpersonal (language enacts human relationship), and textual (language creates the discursive order of reality that enables the other two function".It is cited from the writings of Grzbek (2014), 'Semiotic and Semantic Aspects of Proverbs Study' by Park and Milica [6] by summarizing the three interrelated semiotic categories of proverbs including 'heterosituativity (the meaning of proverb depends on the situation of use), polysemanticity (proverbs have a manifold meaning potential) and polyfunctionality (the same proverb may serve different functions in different contexts'.

\section{Research Methodology}

Methodological Stance of this study includes the philosophical grounds of this research and the tools and techniques of data collection and interpretation. It has also been mentioned that this study will be conducted from the qualitative perspective. The epistemological grounds of anthropological research have been employed including holism, emic approach, cultural relativist perspective and the field data have been collected with the application of qualitative tools and techniques of data collection including the in-depth interview, case study, FGD, key informant 
interview. Hermeneutics is the main epistemological grounds that try to interpret the meaning of an event. In otherwise it is textual or literary analysis. The holistic approach of anthropological research has been employed to understand the whole pictures of people's life including religion, economy, politics and environment. Through this approach, this study will try to find out how the religious, social, economic and ecological issues are related with proverbs and narratives in the village context of Comilla. The emic or cultural relativist approach will also be employed at the time of data collection and interpretation. Emic is an anthropological research perspective that tries to grab the native's point of view; the explanation of various meanings and causation of these three referred folk songs in Bangladesh [7].

In-depth interview technique of field data collection has been employed to gather data. It is informal in nature to get the insights of a specific event. By employing this technique this study will collect data from the respondents who are directly or indirectly involved in such songs in the study areas. Case study is another tool of data collection which is highly practiced by anthropologists and others. Through case studies, data have been collected from the parents how they practice proverbs and narratives to procreate their infants and child care. Focused group discussion technique of data collection will be employed to get data from a group of individuals. FGD has helped to gather multiple insights from the individuals who are directly or indirectly involved in practicing proverbs and narratives related to infants and young children in the study areas [8].

\section{Findings and Analysis}

\section{Proverbs and narratives: an inherited knowledge system of child rearing and caring in rural cultural setting}

The proverbs and narratives in rural cultural setting are related to childcare and rearing are the informal form of knowledge which covers the holistic view i.e. both natural and supernatural elements to identify, distinguish and healing of the health and other mental condition of the children and the infants. The field experience claims that such form of informal knowledge through proverbs and narratives are being endangered because of the practices and the intervention of biomedical knowledge system in rural cultural settings in Bangladesh. In past, people in this rural village applied such indigenous knowledge system in case of diagnosis and healing of heath condition caused by both natural and supernatural elements. People's Informal knowledge is transmitted orally by one generation to another which is rooted from their day to day experiences over natural and supernatural world phenomenon. Their World views and the religious scriptures are clanged together. These bear the basis of their Social and cultural life.

“DohaiSulemanBadshaer (in the name of king Suleman)" - Shimu, a respondent.

People in this study area, utter the name of king Suleman to get rid of from the bad eye of the evil spirit of ghost. The villagers have a belief in ghost, and other demons who are threatened for human beings. King Suleman is a historical legend of Islamic Religion who possessed the power of knowledge to control the ghost by his almighty Allah (Muslims believe that Allah is their creature).

The case of Shimu: the mantra of 'DohaiSulemanbadsha'

Shimu's family is comprised of six members including she herself, her husband, their three sons and only one daughter. Her son Robin is 11 years of age old caught by the ghost. After completing salad, he was sitting under a palm tree at evening. He was caught by fever in the mid night. He was started to shout and move abnormally. Seeing such situation of her boy, Shimmu's mother-in-laws diagnosis that Shimus's boy was caught by ghost as he was sitting under the palm tree at the dark evening (KalSondha). In such situation, both Shimu and her mother-in-laws uttered the verse "DohaiSulemmanbadshaerDohai". They recited again and again this verse getting relief from the ghost. But they did not get fruitful result. Then Shimu communicated with a local hujur (religious specialist) and brought water and amulet given by the hujur. Her mother-in-laws learnt from her mater to recite the verse to get rid of the evil eye of ghost spirit. They frequently recited at the dark evening and dark night even after the curing of Shimu's boy from ghost [9].

Proverbs, narratives and myths are the basis of regulated life pattern of this villager. These cover the get rid of disease sickness and illness, to face trouble of economic and environmental crisis and other livelihood aspects. People take part in ritual like manot (arranging feast in the sacred place), Maintain same taboos during moving home and outside home. These are operated like the informal laws and rules.

Kahir Hossen, A 50 Years of old man stated that "I did not give my child the meat of duck as I Knew that duck meat creates the chance of breathing problem (hapanirog)." He further stated that I took my Children in Krishana Sagordighi (an old watery place in that village like pond) for bath while they were suffering in serious illness. People of this village believe that taking bath at this watery place cures the disease and illness. KabirHossen also provided the knowledge on infants care in the studied village by stating the followings.

"My child was experienced an irregular movement of its brain (amarbaccherbrommochandiosavabikvabelafalafikorsilo). We can observe such movement of my child's head abnormally. For analyzing such condition, we have a myth by saying that a rat has entered into child's head. Seeing this, we rubbed the mixture of mustard oil with water and then my child got rid of such condition."

People also recite rhyme frequently to manage, control and entertain their infants and children. Such type of rhyme composed with linguistic vernaculars of the village setting is highly enjoyed by the infants, young children and the adults.

The sun is shining along with raining,

Fox and vixen's marriage is happening 
(Rod hocche, bristyhocche, khekhsheyalerbiyehocche). FaruqueHossen, a 45 years old age man.

Above this rhyme bears the higher artistic value of integrating the natural elements of rain, sunshine and the behavior of the wild animal. The three incidents are not observed as regular basis and that is why such moment creates artistic value. The infants, children, adolescents and the adult people enjoy such moment as their part of entertainment in rural cultural setting. This rhyme is highly recited by the children while they are playing with their play mates.

Such type of rhyme provides mental/psychological satisfaction for the villagers of all ages, but the infants and children are highly entertained. This artistic creation has done by their effort of bridging knowledge system amongst the cultural ecology, day to day experiences, lexicography or the linguistic vernaculars what they have and put their meanings to their shared cultural meanings [10].

People of this villagers share some common ground of knowledge which roots from their existing belief system in religion, myths and legends. They are assimilated in such belief system which covers the holistic view of life including advice for maintain a sound health, statement on health, livelihood and world views, evaluation of social, cultural and material condition, and even curing of ill health condition and child procreation and rearing. The following statement covers the above addressed elements;

"If a child has been given mother's breast feed, the child's liver growths bigger (bacchakemayerbukerdudhkhawale tar kolizaborho hoi)" - Rina, a 45 years old age woman.

People's knowledge and belief and the caring of infants go hand in hand. Breast feeding is very important for getting a healthy infant to child, and then to being an adult male or female. Here, Rina's belief on child caring and her nature of evaluation on her child growth suggests that she wanted to correlate the relational bondage between the mother's body and her child. By liver growths bigger (kolizaborho hoi), she wanted to mean the child becomes courageous. Like Rina, the other villagers think that breast feeding provides the proper nutrition for the infants. Such narratives provide the nutrient evaluation of child rearing and caring in the studied village.

People in this studied village take part in some rituals and these rituals provide the basis of their life and these are also connected with child rearing and caring. These rituals are encoded their local linguistic jargons and operated through their shared knowledge system which is transmitted orally one generation to the next. The following narratives represent one of the major ritualistic activities of the villagers;

"If a child has been given honey to its mouth, the child speaks sweetly (bacchermukhemodhudile misty kotha koi)" - Sabina, a 40 years old age woman.
Sabina learnt from her mother and adai (traditional birth attendance) that the child speaks sweetly if the child has been given at the time of birth. Not only Sabina but also her other community members share such evaluation of the ritual and the children speech behavior. Although the relationship between giving honey to the child's mouth at the time of birth and sweet speech at the time of speaking is arbitrary. In other word, Sabina did not provide any proposition to the concrete relationship of her addressed narrative. However, either this ritual makes the child to speak sweetly or not the villagers believe such and practice as the integral part of child and infants rearing and caring in their local cultural settings [11].

People of this village also have some other ethno poetic genres like proverbs, rhyme, riddle and narratives to care about mother and infant's health caring although they do not provide about the origin of such artistic activities such as who told first or who were the founder of such oral literature. Some of the proverbs on mother and infants caring are provided below with their meanings in the villager's context.

"If the mother and infants eat palm fruit, they feel digestive problems (maichayekhailetal, petebadhegolmal)" - Saleha, a 49 years old age woman.

People in this studied village know that eating palm fruit is not so good for the stomach health of the both mother and infants at it creates the risk of digestive problems. Although they did not provide the medical/modern scientific reasons, they follow this connotation as an essential part of their food behavior during pregnancy, infants and childcaring, and even the adults and adolescent maintain restriction and prevention to eat palm fruits.

"Mangshokhelemangshobarhe, shakkhelemolbarhe (meat growths meat, red leaf/green leaf causes over toilet)" - Manjura, a 60 years age of old woman.

Manjura knows from her older generation about the food behavior of human especially for infants, children and the adolescent who are at the growing up stage. She believes that meat growth meats in human body although she does know how to explain it. Overeating of red leaf or other green leaf causes over toilet for infants, child and mother. Although she believes and maintains the above addressed narrative, this does not mean that she does not provide green leaf or red leaf to her grandchildren or she always suggests providing meat to them. This narrative is just a guideline to them. Another notion has been contained within the above narrative that is green leaf or red leaf causes the chances of higher toilet. In such situation, people who suffer in highly constipation (kostokathinno), they may get relief by eating green leave/red leaf.

Some other linguistic genres are also found among the villagers who play a vital role as advices, evaluation, beliefs, and taboos for regulation rural lives of either individual or collective gathering. This connotations and linguistic jargons bear the pragmatic value of rural live. These are (Table 1) 
Table 1: The presentation and the interpretation FGD data. Source: Fieldwork: 2018.

\begin{tabular}{|c|c|}
\hline Proverbs/Narratives & Meanings in Cultural Context \\
\hline $\begin{array}{l}\text { Leave the character of cuckoo and receive the character of crow } \\
\text { (kokilersovab tag koro, kakersovabgrohonkoro). }\end{array}$ & $\begin{array}{l}\text { a) It suggests being a man/woman of self-sacrificing not to be like the selfish } \\
\text { character like cuckoo. } \\
\text { b) The cuckoos lay eggs to the crow's nest and eat the crow's eggs. } \\
\text { c) The crows do the entire parental role to procreate the infants of cuckoo. } \\
\text { d) It suggests loving to others. }\end{array}$ \\
\hline $\begin{array}{l}\text { The kin member who early provides the clothes to baby, the } \\
\text { baby will be lovelier to his or her (baccha jar kaporh age porhbe, } \\
\text { baccha tar voktohobe). }\end{array}$ & $\begin{array}{l}\text { a) People of this village believe that this activity make an eternal bondage between } \\
\text { the gift giver and the gift receiver. }\end{array}$ \\
\hline $\begin{array}{l}\text { The older generation makes to the route to the next generation } \\
\text { (ager haljemne jai, porerhal o temne jai) }\end{array}$ & $\begin{array}{l}\text { a) The younger generation has a debt to their older generation. } \\
\text { b) The experiences of the previous actions predict the next actions. }\end{array}$ \\
\hline $\begin{array}{l}\text { It is not good to sit in front of the door of a room } \\
\text { (ghorerdorojarsamnebostenei). }\end{array}$ & $\begin{array}{l}\text { a) People believe that the angels cannot enter into the room due to man sitting in } \\
\text { front of door. } \\
\text { b) It looks odd and destroys the beauty of room. }\end{array}$ \\
\hline It not good to sit over the pillow (balisheruporbostenei). & $\begin{array}{l}\text { a) People believe that it causes cyst in the lower part of hip. } \\
\text { b) People have a respective value by saying it is not good to sit over the pillow while } \\
\text { they keep the head over pillow as head contains face and face is the most beautiful } \\
\text { than hip. } \\
\text { c) People believe that it causes back pain. } \\
\text { d) This taboo makes a chance not to provide dusts by the children in rural settings. }\end{array}$ \\
\hline $\begin{array}{l}\text { It is not healthy to take food before taking the brash } \\
\text { (mukhnadhuyekisukhetenei). }\end{array}$ & $\begin{array}{l}\text { a) A taboo which regulated a healthy life. } \\
\text { b) It suggests washing the germs and bacteria from mouth. }\end{array}$ \\
\hline $\begin{array}{l}\text { It is not healthy to take the over burnt food } \\
\text { (purhakahbarkhetenei). }\end{array}$ & $\begin{array}{l}\text { a) It makes a human as bad luck holder. } \\
\text { b) It creates the probability of food poisoning. }\end{array}$ \\
\hline $\begin{array}{l}\text { It bears the bad signs to eat the oil fried cake while walking } \\
\text { outside road (televajapithakhetekheterastai hate nei). }\end{array}$ & $\begin{array}{l}\text { a) There might be a chance to fall in danger by ghost spirits or other demons. } \\
\text { b) Allah, the creature of Muslim does not like to eat at the time of standing and } \\
\text { walking. }\end{array}$ \\
\hline
\end{tabular}

Above this discussion represents people's common ground of sharing of knowledge rooted from their culture where culture covers their whole aspects of life including knowledge, beliefs and evaluation of the world views having the collective organization of knowledge creation, evaluation and transitory process of sharing one generation to the next. They share such narratives and proverbs as their basis of child procreation as well as day to day interaction in rural cultural settings [12].

\section{Concluding Remarks}

From the above interpretation of the field experience, there is still some practices of people's indigenous form of knowledge system to procreate and rearing their infants, children and mother's who gave birth already and expected to be mother despite the dominancy of modern knowledge system. Proverbs and narratives in rural cultural settings cover the whole aspects of life including human relationship, the nature of categorizing and identifying natural and supernatural elements, the livelihood aspects etc. This form of oral literature of the people which bears the experiential knowledge of people needs to be recorded. As it is transmitted orally, this knowledge will be erased if the younger generations remain far behind their older generation. Further research, academic and institutional initiatives should be taken to record and analyze such form of knowledge system which is produced and transmitted by the locales in the form of proverbs and narratives.

\section{References}

1. Appadurai A (1996) Modernity Write Large: Cultural Dimension of Globalization. University of Minnesota Press, USA.

2. Bowman DW (1998) Philosophical Perspective on Music. Oxford University Press, USA

3. Bruno N (2005) The Study of Ethnomusicology: Thirty-One Issues and Concepts. University of Illinois Press, USA.

4. Fetterman DM (1998) Ethnography Step by Step.

5. Geertz C (1973) The Interpretation of Culture. California University press, USA.

6. Jeong O Park, Joan Milica (2016) Proverbs as Artistic Miniatures: A Stylistic Approach. RRL, LXI (4): 379-403.

7. Liljestorm S (2011) Emotional Reactions to Music: Prevalence and Contributing Factors.

8. Merriam A (1964P) The Anthropology of Music. III: Northwestern University Press, USA

9. Powers WK (1980) Oglala Song Terminology: Selected reports on Ethnomusicology.

10. Said E (1978) Orientalism. Pantheon, New York, USA.

11. Spradly JP (1998) Participant Observation. 
12. Stock K (2007) Philosophers on Music: Experience, Meaning and Work. Oxford University Press, USA.

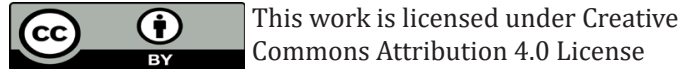

To Submit Your Article Click Here:

Submit Article

DOI: $10.32474 / J A A S .2019 .01 .000109$

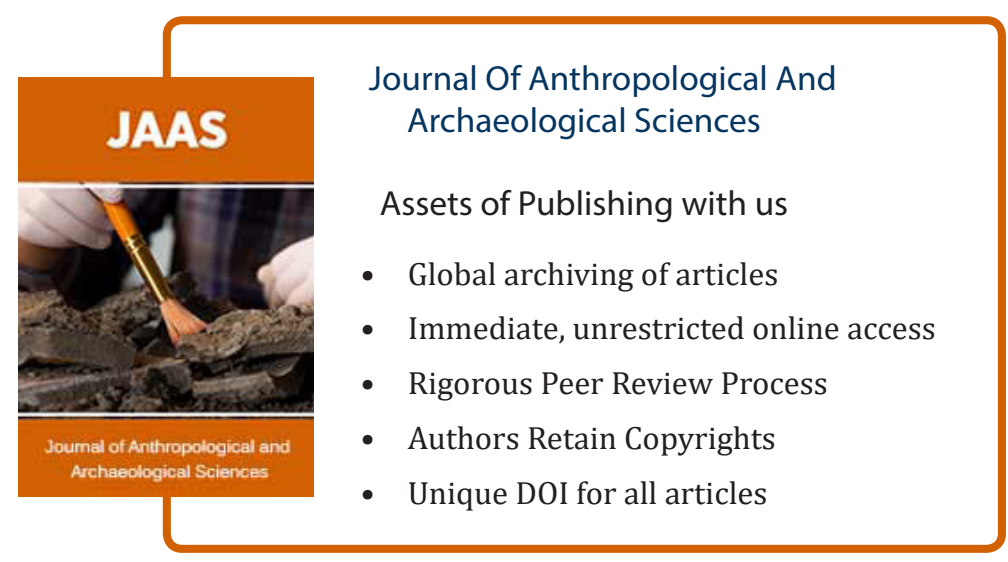

